\title{
Squamous Papillomas in the Trachea and Main Bronchi Found in a Cowden's Disease Patient
}

\author{
Takehito Shukuya, Satoshi Hirano, Haruhito Sugiyama, \\ Nobuyuki Kobayashi and Koichiro Kudo
}

Key words: Cowden's disease, bronchoscopy, trachea, bronchus, papilloma

\section{(DOI: 10.2169/internalmedicine.45.1716)}

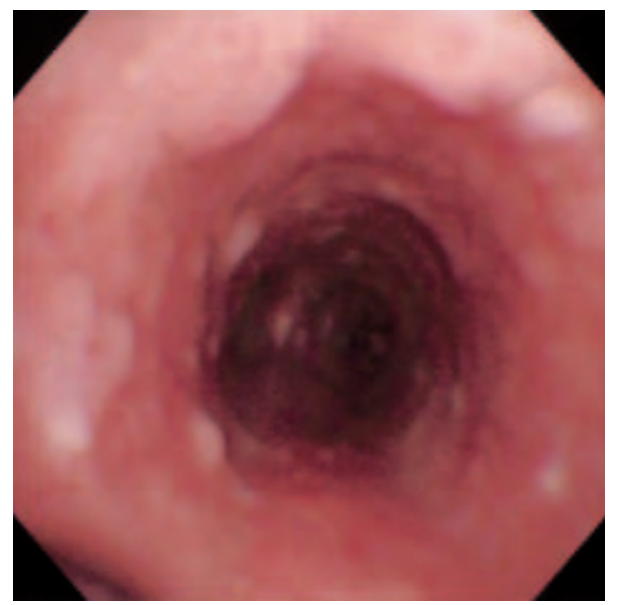

Figure 1. Bronchoscopic examination in the trachea and main bronchi revealed white flat torus lesions the diameter of which ranged from 3 to $5 \mathrm{~mm}$.

\section{Text}

A 58-year-old man was admitted to our hospital under the chief complaints of chronic cough and sputum. He had previously fulfilled the diagnostic criteria proposed by Salem and Steck, and had been diagnosed as having Cowden's disease at the age of $36(1,2)$. Bronchoscopy in the trachea and main bronchi revealed white flat torus lesions the diameter of which ranged from 3 to $5 \mathrm{~mm}$ (Fig. 1). A biopsy of the lesions showed squamous papillomas (Fig. 2).

Cowden's disease is usually inherited as an autosomal dominant condition and is characterized by multiple hamartomatous malformations. The most consistent findings are the mucocutaneous lesions that include oral papillomas, and acral and palmoplantar keratoses (2). Hamartomatous polyps in the gastrointestinal tract are also seen (3).

Bronchoscopic finding in Cowden's disease have never been reported. The squamous papillomas found in the trachea and main bronchi were macroscopically and histologically similar to oral, laryngeal and pharyngeal papillomas in previous reports $(4,5)$. These lesions seemed to be related to Cowden's disease. 


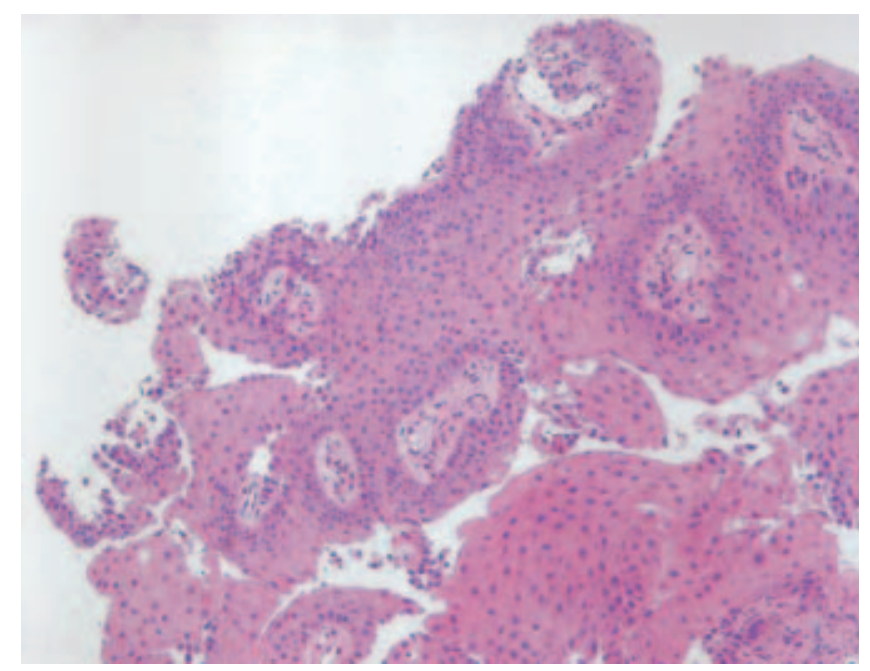

Figure 2. Bronchial biopsy of the lesions revealed squamous papillomas (HE stain, $\times 400$ ).

\section{References}

1. Hisato H, Hirata K, Watanabe N, et al. A case of Cowden's disease. Nihonnaikagakkaizasshi 73: 48-54, 1984 (in Japanese).

2. Salem OS, Steck WD. Cowden's disease (multiple hamartomatous syndrome). J Am Acad Dermatol 8: 686-696, 1983.

3. Schreibman IR, Baker M, Amos C, et al. The Hamartomatous polyposis syndromes: A clinical and molecular review. Am J Gastroenterol 100: 476-490, 2005.

4. Smid L, Zargi M. Cowden's disease-its importance for otolaryngologists. J Laryngol Otol 107: 1063-1065, 1993.

5. Botma M, Russell DI, Kell AR. Cowden's disease: a rare cause of oral papillomatosis. J Laryngol Otol 116: 221-223, 2002.

(C) 2006 The Japanese Society of Internal Medicine http://www.naika.or.jp/imindex.html 